\title{
Política Cotidiana y Tolerancia en las obras de John Locke y Robert Nozick
}

\author{
Sergio Morresi \\ smorresi@gmail.com \\ Universidade de General Sarmiento, Buenos Aires, Argentina
}

\begin{abstract}
resumen En 1974, Robert Nozick publicó *Anarquía, Estado y Utopía*, una obra que, por primera vez, otorgaba estatus teórico a una de las corrientes del pensamiento neoliberal: el libertarianismo. En buena medida, el texto de Nozick se reclama como una relectura en clave de filosofía analítica de la teoría política de John Locke. En este artículo se ofrecen algunos argumentos para mostrar que, aunque la perspectiva de Nozick presenta ciertas similitudes retóricas con la obra del filósofo inglés, en cada uno de los puntos fundamentales (como por ejemplo la idea de derecho, la noción de persona, el papel de la política y los conceptos de justicia y bien público) Nozick se aparta claramente de las premisas lockeanas. Como conclusión, se sostiene que al alejarse de la concepción lockeana, Nozick defiende una sociedad en la que la política está ausente y en la que el Estado aparece, paradójicamente, menos limitado que en las concepciones liberales clásicas.
\end{abstract}

palabras clave John Locke; Robert Nozick; Liberalismo; Bien Público; Política

La publicación de Anarquía, Estado y Utopía (NOZICK, 1991, en adelante AEU) abrió dio paso a muchas reseñas críticas. En varias de estas reseñas se señaló que lo que tan polémicamente afirmaba Nozick (la imposibilidad de que un Estado más allá del Estado mínimo fuera aceptable moralmente) no era más que una traducción de las ideas de John Locke a una filosofia analítica y atea. Desde entonces, ha pasado mucho agua bajo el puente. Por un lado, los estudios contextualistas sobre Locke que se habían iniciado con los trabajos de Laslett (1988) y Dunn (1986) se multiplicaron, poniendo en duda algunas certezas sobre el papel de la 
teoría lockeana en la conformación del liberalismo (TULLY, 1993). Por el otro, aunque siguieron apareciendo trabajos académicos sobre Nozick, los temas planteados por el filósofo norteamericano se volvieron ejes de discusión política más que teórica (FESER, 2004). En este sentido, no es de extrañar que las ligazones entre el pensamiento de Locke y el de Nozick que los primeros críticos habían resaltado (por ejemplo, SINGER, 1976; COLEMAN, 1976; DAVIS, 1976) hayan pasado a segundo plano en los últimos años. Si, a pesar de ello, nos proponemos aquí regresar a ese ángulo de lectura no es para volver a señalar las similitudes entre Locke y Nozick, sino para concentrarnos en sus diferencias. Pensamos que este es un buen modo de mostrar si hay de nuevo en el neoliberalismo libertariano de Nozick.

\section{De los valores a los individuos}

Locke partía de la idea de que el hombre tenía derechos porque, a diferencia de las otras criaturas, es un ser racional; esa racionalidad le permitía al hombre guiarse por la moral y, justamente por poseer acceso a esta guía, se podía afirmar que el hombre es libre y que su libertad es un derecho positivo (cf. LOCKE, 2001, II.4-15, pp. 381-394). Nozick, en cambio, afirma que los hombres tienen derechos simplemente porque están separados los unos de los otros. En AEU el carácter de sujeto de derecho del hombre se presenta apenas como axioma, pero en un texto posterior, Explicaciones Filosóficas (NOZICK, 1981), Nozick busca dar sustento a la deducción de los derechos más allá simple hecho estético de la vida separada. Para Nozick, se puede considerar valioso a aquello que consigue conciliar la diversidad en una totalidad sin desnaturalizar los elementos constitutivos. El ser humano sería valioso porque su humanidad no reside en la suma de los átomos que lo componen, sino en la armonización única e irrepetible que él es. Esta armonización, adquiere sentido al vincularse positivamente, como contribución, a una entidad aún más amplia: la sociedad como suma de individuos. O sea, el hombre, que en sí mismo es unidad de una diversidad (y por lo tanto valioso) le da sentido a su valor al unirse a una sociedad que lo incorpora en una armonía mayor. 
Aún aceptando la controversial idea de vincular la concepción de "diversidad en la unidad" a un valor, ¿cómo podemos extraer derechos del "valor" de la naturaleza humana? La respuesta de Nozick es pasmosamente simple: el hombre, en tanto es un ser valioso y dispone de libre arbitrio, puede darle sentido a su vida contribuyendo a la formación de una entidad más amplia y, así, originar valor. En este sentido, somos responsables del valor y por ello merecemos respeto. Este merecimiento de respeto funda nuestros derechos que deben ser entendidos como una coraza que rodea y protege esa armonización valiosa que somos. Por ello para el filósofo norteamericano "los derechos de los demás determinan las restricciones de nuestras acciones" (NOZICK, 1991, p. 41); es decir, los derechos se nos aparecen como "restricciones morales indirectas" (moral side constraints, en adelante RMI), no diciéndonos lo que debemos hacer sino aquello que no debemos hacer (no matar, no violar la propiedad ajena). Se trataría, entonces, como dice Álvaro De Vita (2000, pp. 53-56) más bien de "deberes" que de derechos. Pero, en realidad, las restricciones no son deberes en el sentido habitual. En la teoría lockeana, el deber natural de un hombre implicaba un determinado tipo de comportamiento, una obligación moral consigo mismo y con la humanidad (por ejemplo, la obligación de ser caritativos, LOCKE, 2001, I.42, p.244). Para Nozick, el deber (o, mejor, el derecho puramente negativo) no aparece como una afirmación, sino como una prohibición.

En las teorías basadas en derechos, la noción de deber es derivada del derecho, por eso "el Estado debe empeñarse en proteger y promover determinados intereses de todos los individuos" de modo tal que "el ideal es aproximarse tanto como sea posible a un estado de cosas en el que todos los ciudadanos encuentren condiciones propicias para el ejercicio de sus derechos individuales" (DEVITA, 2000, p. 55). Este es el caso Locke, pero no el de Nozick. En el Estado de Naturaleza lockeano, los hombres son jueces y ejecutores no sólo de sus propias causas, sino de todas, pues el transgresor -quien me roba, por ejemplo- no sólo está violando "mi" derecho a la propiedad, sino "el" derecho a la propiedad, que es un derecho de toda la humanidad (LOCKE, 2001, II.6, pp. 384385). Por eso, al constituirse un Estado, éste tiene la potestad de obligarme a cumplir con mis deberes y de castigarme en caso de incumplimiento (LOCKE, 2001, II.88, p. 459). Para Nozick, en cambio 
En un estado de naturaleza un individuo puede, por sí mismo, imponer sus derechos, defenderse [...] Otros, a su llamada, pueden unírsele en su defensa [...] ya sea porque tienen espíritu cívico, porque son amigos, porque fueron ayudados en el pasados o porque quieren que se los ayude en el futuro, o a cambio de algo" (NOZICK, 1991, pp. 25, énfasis añadido).

Mientras que para Locke los hombres deben defender los derechos (suyos y de sus semejantes), en Nozick pueden hacerlo o no, ya que desde su perspectiva lo importante es no transgredir las RMI. En otra palabras, mientras la Ley de Naturaleza lockeana me interpela a actuar en mi defensa y en la de mis hermanos, la prudencia nozickiana me lleva a actuar como mejor me parezca sin quebrar las RMI que se me imponen. De acuerdo con Locke, uno no podría asistir impávido a un intento de asesinato; en cambio, de acuerdo con Nozick para ser moral basta con que uno mismo no sea al asesino, porque nuestro deber no es impedir o castigar los crímenes, sino abstenernos de cometerlos.

En todo caso, para Nozick los derechos existen (porque los seres humanos somos merecedores de respeto), son naturales (porque son comunes a todos y no dependen de ninguna persona u organización particular), son negativos (es decir, son derechos de no interferencia), no pueden positivarse (no pueden expresarse como deberes, ya que su única forma legítima es la de RMI) y son exhaustivos (no se pueden presentar conflictos entre ellos) ${ }^{1}$. Ahora bien, una vez que aceptamos que los derechos existen y tienen las características que Nozick les adjudica, cabe la pregunta acerca su contenido. Nozick no establece un listado taxativo de derechos o RMI, pero de la lectura de AEU puede deducirse que existen varios que al filósofo norteamericano le parecen importantes (de propiedad, a expresarse libremente, a contratar y comerciar). Sin embargo, como afirmaron algunos comentadores (WOLFF, 1991), para Nozick todos estos derechos parecen "derivados" de un derecho que resultaría primordial: el de de la auto-propiedad. El argumento de Nozick sería el siguiente: si una persona $\mathrm{X}$ es dueña de sí misma puede hacer consigo todo aquello que quiera (siempre y cuando eso que quiera no implique violar la propiedad que otro sujeto $\mathrm{Y}$ tenga sobre sí mismo, pues cada sujeto está protegido por la coraza de RMI) y nadie puede hacer con ella algo a menos que ella misma consienta. El derecho de la auto-propiedad 
es, pues, el derecho a disponer de la propia persona del mismo modo que un amo puede disponer de un esclavo; es un derecho absoluto que el hombre tiene sobre sí mismo. Asi, las RMI servirían como protección al ejercicio de la auto-propiedad.

Nozick (1991, p. 43) afirma que "las restricciones indirectas a la acción reflejan el principio kantiano subyacente de que los individuos son fines, no simplemente medios". Parece por lo menos irónico que Nozick pretenda basarse en Kant para justificar su argumento del individuo como un señor sobre sí mismo, ya que el filósofo de Königsberg rechazaba por completo el principio de auto-propiedad. En sus Lecciones de ética, Kant (1988) afirmaba que el concepto de propiedad sobre uno mismo era incoherente: una entidad sólo puede ser una cosa a la vez; por lo tanto no puede afirmarse que un hombre sea un sujeto poseedor y a la vez un objeto poseído. De este hecho, Kant deducía que la libertad personal no podía incluir, por ejemplo, el derecho a ejercer la prostitución o a dañarse a uno mismo $^{2}$. De todas formas, para percibir la incompatibilidad entre el modelo kantiano y el modelo de Nozick no hay más que recurrir a la segunda formulación del imperativo categórico en la que el filósofo estadounidense afirma basarse: "Obra de tal modo que te relaciones con la humanidad, tanto en tu persona como en la persona de cualquier otro, siempre como un fin y nunca solamente como un medio". Con esta fórmula Kant deja clara la internalización de nuestro deber para con la humanidad en la cual está incluida nuestra propia persona, de modo que no sólo se nos exige que no forcemos a otros sujetos sino que tampoco nos esclavicemos a nosotros mismos.

Sin embargo, podría argumentarse que Nozick no busca presentarse como neo-kantiano, sino como neo-lockeano. ¿No fue Locke uno de los primeros en sostener que el hombre disfruta de propiedad sobre sí mismo? Es verdad que Locke basa al menos parte de su teoría en la idea de que el hombre disfruta de algún tipo de propiedad sobre sí; empero a diferencia de las tesis de Nozick, Locke no supone que la auto-propiedad sea un derecho absoluto. Locke consideraba que el hombre es la criatura de un ser todopoderoso y por lo tanto está obligado hacia su creador (OLIVECRONA, 1974a; 1974b). En este sentido, el hombre de Locke dispone de su propia persona de un modo condicionado: el trabajo de su cuerpo y la labor de sus manos puede decirse que son suyos de la mismo 
modo en que él es de Dios. Dicho de otro modo, el hombre lockeano es propietario de sí mismo sólo de una manera supeditada y hay acciones que no está en su mano realizar (e, inversamente, hay caminos que debería seguir aun contra sus inclinaciones). El hombre de Locke, por ejemplo, no tiene derecho al suicidio (WINDSTRUP, 1980) o a venderse voluntariamente como esclavo (LOEWENBERG, 1985) porque siempre está obligado a seguir la Ley de Naturaleza que es "eterna e inmutable" y lo manda a proteger su vida, su libertad y sus posesiones y las del resto de la humanidad (LOCKE, 2001, II.6, pp. 384-385). El hombre de Nozick, en cambio, puede (sin violar los derechos de nadie) quitarle todo valor a su vida y entregarse a sí mismo a una máquina de la experiencia (NOZICK, 1991, pp. 53-56), venderse como esclavo (NOZICK, 1991, p. 317), quitarse la vida o dejar que se la quiten (NOZICK, 1997, p. 142) e incluso dañarse a sí mismo para obtener un bien. Así, el individuo de Nozick, teóricamente limitado por los derechos negativos de sus congéneres, parece sin embargo, libre de hacer consigo mismo cualquier cosa que sea capaz de imaginar. Así, el argumento de Nozick invierte al de Locke:este último partía de los derechos y obligaciones naturales para llegar al concepto de propiedad; el primero toma como punto de partida la (auto)propiedad y de ella extrae las RMI.

\section{De los Individuos al Estado Mínimo}

Nozick (1991, pp. 17-22) establece que a su criterio la mejor forma de saber si el Estado podría surgir de modo legítimo (es decir si podría aparecer sin violar las RMI) es tomar como punto de partida a "la mejor situación anárquica que uno pueda esperar" como, por ejemplo, el Estado de Naturaleza tal como lo describe Locke en sus Dos Tratados. En ese Estado de Naturaleza, los individuos que disfrutan de propiedad sobre sus propias personas pueden vivir armoniosamente. Empero, siempre existe la posibilidad de que se genere una violación a la RMI y por ello sería lógico que los hombres respetuosos de la moral se agruparan para protegerse mutuamente (NOZICK, 1991, pp. 23-24). No se trataría, con todo, de un Estado, sino de agencias de protección. Pero estas instituciones, piensa Nozick, serían inestables e ineficientes. Para evitar esta ineficiencia 
sería preferible recurrir a la división del trabajo, contratando agencias (empresas) de seguridad que ofrezcan sus servicios profesionales en el mercado (NOZICK, 1991, pp. 24-28).

Ahora bien, a medida en que surgieran agencias de seguridad, sería lógico que compitieran ente ellas, hasta que alguna resultase triunfante. Esta agencia no sería un todavía un Estado por dos razones: 1) un Estado ejerce un monopolio total no sólo sobre aquellos que voluntariamente participan de él, sino sobre todos los habitantes de un determinado territorio y 2) un Estado protege a todos los hombres que se encuentran dentro de su campo de acción, independientemente de que ellos hayan decidido formar parte de la asociación. Sin embargo, podría considerarse que una vez que la agencia se haga con una posición efectivamente dominante, nos encontraríamos ante una situación "intermedia" entre la anarquía pura y el Estado mínimo, lo que Nozick llama un Estado ultra-mínimo.

Un Estado ultra-mínimo mantiene un monopolio sobre todo el uso de la fuerza con excepción del que es necesario en la inmediata defensa propia y por lo tanto excluye la represalia privada (o la proporcionada por una agencia) por daño y para exigir compensación. Sin embargo, únicamente ofrece protección y servicios de ejecución a aquellos que compran sus pólizas de protección y aplicación (NOZICK, 1991, p. 39).

Una vez que se ha llegado a esta situación, sostiene Nozick, el paso hacia la conformación de un Estado mínimo no sería difícil, pues la agencia dominante (Estado ultra-mínimo) reclamaría para sí el monopolio de la fuerza, pidiéndole a los individuos que todavía no se le han adherido que lo hagan a pesar de que no les convenga (por ejemplo, porque ellos se pueden defender por sí mismos). Por ello sería lógico que los compense y la forma obvia y sencilla de hacerlo es ofreciéndoles el servicio de protección de forma gratuita. Así se llega finalmente a un Estado en toda regla.

[...] la transición de un Estado ultra-mínimo en un Estado mínimo tiene que ocurrir moralmente. No sería moralmente permisible para las personas mantener el monopolio en el Estado ultra-mínimo sin ofrecer servicios de protección para todos, aunque esto requiere una redistribución especifica. Los operadores del Estado ultra-mínimo están moralmente obligados a producir en Estado mínimo (NOZICK, 1991, p. 62). 
De esta forma, se ha realizado la transición del Estado ultra-mínimo al Mínimo "sin violar los derechos de nadie" (NOZICK, 1991, p. 62) pues el monopolio de la fuerza surge "por un proceso de mano invisible" y "a través de medios moralmente permitidos" (NOZICK, 1991, pp. 118-122).

Hasta este punto, AEU presenta una visión clásicamente liberal del Estado gendarme de Spencer, aunque con la llamativa ausencia de la noción de Bien Público, presente a lo largo de los textos de Locke (2001, II.3, p. 381; 1999, p. 35), y que a Nozick (1991, pp. 40 y ss.) le parece un galimatías o una deformación utilitarista ${ }^{3}$. Pero es justamente en este punto donde la comparación entre Locke y Nozick se vuelve realmente interesante, pues precisamente aquí Nozick parece seguir más de cerca los argumentos de Locke y, paradójicamente, más se aleja de él. Porque si Locke (II.134, pp. 503-504 y II.12, p. 391) buscaba alcanzar el Bien Público por medio de la acción de un gobierno civil que se guiara por la Ley Natural, Nozick (1991, p. 153) sostiene que "el Estado mínimo es el máximo que se puede justificar”, ya que cualquiera más extenso violaría las RMI.

Para defender la imposibilidad de extender el Estado más allá del mínimo, Nozick introduce una "teoría de las titularidades" que, desde su punto punto de vista, le permite derrotar las visiones que buscan un Estado más allá del mínimo basándose en ideas como el Bien Común y la Justicia Social. Esta teoría de las titularidades tiene "aires lockeanos" porque está basada en una versión debilitada de la cláusula de la suficiencia de Locke (que exigía que al apropiarnos de algo debíamos dejar "suficiente y tan bueno" del mismo bien que tomábamos para el resto de la humanidad) y también porque parece seguir el principio de que la propiedad sobre el cuerpo da derechos sobre el producto del trabajo (LOCKE, 2001, II.27, pp. 407-409; cf. SREENIVASAN, 1995, pp. 120 y ss). Sin embargo, las diferencias entre Nozick y Locke respecto a la propiedad son varias y profundas (nos limitaremos a señalar dos, pero pueden encontrarse otras en DRURY, 1982 y COHEN, 1995).

En primer lugar, Nozick supone que el mundo natural no es de nadie y que por lo tanto las adquisiciones originales se basan en la ley del primer ocupante (FESER, 2005). Locke, en buena medida porque necesitaba oponerse a los planteos patriarcales de Robert Filmer, presuponía que el mundo natural era propiedad común de la humanidad (LOCKE, 
2001, II.25, p. 406) y por eso dedicó parte del capítulo V del Segundo Tratado a explicar cómo particular podía apropiarse de algo.

En segundo lugar, el tipo de derecho de auto-propiedad en el que piensa Nozick es absoluto y exclusivo, consecuentemente, la titularidad de un agente sobre una parte del mundo natural también es absoluta y exclusiva (aunque en ciertos pasajes admite la "superación" de los derechos en situaciones de catástrofes naturales, NOZICK, 1991, p. 181). En el caso de Locke, dado que la auto-propiedad es condicionada y considerando que el mundo natural es propiedad común de la humanidad, toda titularidad de un individuo está sometida a un doble control: el consentimiento de los otros (sea tácito como en el Estado de Naturaleza o sea positivo como en la Sociedad Civil) y, más importante aún, la obediencia a la Ley de Naturaleza que manda a cada individuo no sólo a proteger su vida, su libertad y sus bienes, sino también la vida, la libertad y los bienes de todos aun cuando existan leyes positivas que regulen la propiedad (LOCKE, 2001, II.30-31, pp. 411-412).

Ahora bien, si el mundo no es una reserva de recursos para que se sirva el primero en llegar, entonces deben buscarse argumentos que autoricen a los individuos a apropiarse de partes de la naturaleza. Ese fue el problema que Locke enfrentó y superó con una compleja y potente argumentación que mantenía en pie los limites morales a la apropiación pero que mostraba cómo los mismos podían (e incluso debían) ser superados a nivel fáctico al introducirse una teoría del valor (MORRESI, 2009, pp. 208-215). Pero Nozick (1991, pp. 176 y ss.) desconfia de esa línea argumentativa y parece dar por sentado que los títulos que adquieren los individuos sobre la naturaleza son absolutos y exclusivos. Este es el verdadero quid de la cuestión. Porque si los títulos de propiedad sobre el mundo natural son absolutos y exclusivos, todos los límites (consensuales y morales) lockeanos a la propiedad son derrotados. Así, cuando Nozick afirma adherir a un versión "debilitada" de la cláusula lockeana de la suficiencia, está, en realidad, introduciendo apenas una complicación lateral a su argumentación. En efecto, Nozick no desarrolla la vía argumentativa de Locke porque el tipo de propiedad que obtendría de hacerlo estaría supeditado a un derecho superior y, entonces, toda su teoría caería bajo el peso de ese "derecho original", que en el caso de Locke equivalía a la Ley Natural ${ }^{4}$. 
Si Nozick aceptara la Ley Natural de Locke (o alguna versión moderna y atea de un deber a priori que rebasara las titularidades) podríamos afirmar que tiene un planteo neo-lockeano. Sin embargo, en este punto, Nozick parece apenas servirse retóricamente de los argumentos de Locke. Ese uso instrumental queda aún más claro cuando dirigimos nuestra mirada a la cotidianidad del Estado mínimo. En la visión lockeana, al introducirse el gobierno representativo, las libertades individuales se convierten en derechos y deberes positivos (legalmente exigibles); al hacer esto, hace su aparición (de modo embrionario, es cierto) una esfera pública que es la que hace posible la vida dentro de la comunidad política. En la teoría de Nozick, las cosas son bien diferentes: el Estado no es un momento político, sino una mera agencia administrativa con "funciones de protección" (de las RMI)5 ${ }^{5}$ Es justamente en este punto donde la argumentación de Nozick se revela más endeble y, paradójicamente, más sugerente.

\section{De lo justo a lo utópico}

En la tercera parte de AEU, Nozick admite que, a pesar de ser moral, el Estado mínimo no sería un proyecto sugestivo de vida en común. Sin embargo, se apresura a explicarnos que no precisamos limitarnos a tomar al Estado mínimo como el único posible, sino que deberíamos considerarlo "como un marco" para cualesquiera proyectos de vida que pudieran ser imaginados (y aceptados).

Cualquier grupo de personas puede diseñar una pauta y tratar de persuadir a los otros para que participen en la aventura de una comunidad según esta pauta.Visionarios y excéntricos, maniáticos y santos, monjes libertinos, capitalistas, comunistas y demócratas participantes, proponentes de falanges (Fourier), palacios de trabajo (Flora Tristán), pueblos de unidad y cooperación (Owen), comunidades mutualistas (Proudhon), tiendas de tiempo (Josiah Warren), Brudherhof, kibbutzim, kundalini yoga ashrans, etcétera, todos pueden hacer su intento al construir una visión y establecer un ejemplo atractivo (NOZICK, 1991, p. 304). 
Aun admitiendo que la amplitud de la propuesta parece "estimulante", surgen dudas y problemas:, ¿estas sociedades no estarían, acaso, reñidas con el respeto a las RMI? Después de todo, Nozick no está hablando aquí de elecciones individuales, sino colectivas, y las colectividades, al menos las que menciona Nozick, pueden obligar a sus miembros a cumplir con ciertos deberes que rebasarían las RMI de los individuos. Más aún, en la medida en que estas sociedades pudieran realizarse plenamente y dado que no comparten necesariamente un "espíritu de tolerancia mutua", la colisión entre las distintas utopías parece probable. Por último, podría temerse que el amplio marco planteado por Nozick pudiera arrojar como resultado posible un Gran Hermano universal.

Desde la perspectiva de Nozick, el panorama oscuro que imaginamos podría conjurarse porque las pautas de las comunidades deberían estar de acuerdo con los metaprincipios del Estado mínimo (respeto por la integridad, la libertad y la propiedad de cada individuo). Sin embargo, esto no parece ser del todo coherente: una sociedad al estilo de Owen, por ejemplo, no tendría por qué respetar las RMI de cada individuo. Aún así, podría decirnos Nozick, no se trata de que una comunidad en particular respete las RMI hacia sus miembros (puede hacerlo o no), sino que las mismas sean respetadas como metaprincipios. Así, la idea de Nozick no sería que todos vivamos de acuerdo con las reglas del Estado mínimo, sino que el Estado mínimo sea un marco dentro del cual las personas puedan, voluntariamente, formar distintas comunidades (en una suerte de mercado de proyectos sociales) que podrían regirse internamente por las reglas del Estado mínimo o por otras cualesquiera que sus miembros decidan. Pero, si fuera así, ¿cómo asegurar que las personas verían salvaguardados sus derechos? Porque, en caso de que no les gustara la comunidad en la que nacieron, pueden emigrar libremente a otra que fuera de su agrado (o fundar una nueva).

Aquí hay varios problemas implicados, vamos a comenzar mencionando las cuestiones menores. En primer lugar, Nozick parece ignorar por completo que la votación con los pies implica costos, a veces prohibitivos (FRIED, 2003) ${ }^{6}$. En segundo término, la emigración de sus miembros es un costo para las comunidades de las cuales quieren partir ${ }^{7}$. En tercer término, los individuos que nacen en comunidades (incluso en comunidades como la del Estado mínimo) tejen redes sociales, son mol- 
deados por cierto tipo de educación formal e informal que puede hacer imposible la opción real de emigrar (no nos estamos refiriendo al extrañamiento del auto-exilio, sino a la imposibilidad de plantearse la opción). En cuarto lugar, para algunas comunidades la mera existencia de ciertas opciones es ofensiva y podría (legítimamente) no informar a sus ciudadanos con respecto a posibles opciones, ¿o acaso sería imaginable que una comunidad evangelista informe a sus miembros que pueden, si así lo desean, emigrar hacia una comunidad libertina? (NOZICK, 1991, pp. 315-317).

Pero hay otros inconvenientes más importantes en la idea de Nozick. De acuerdo con su planteo, todas las comunidades podrían ser libremente aceptadas si se enmarcaran dentro del Estado mínimo. En principio, ello implicaría solamente que las comunidades deberían tener sus fronteras abiertas para que los que objeten sus reglas internas puedan retirarse. Así, parece que al fin y al cabo lo que hace aceptable a una forma de vida no es el respeto por las RMI sino, apenas, el consentimiento hipotético y la existencia de alternativas (al menos hipotéticamente, una de estas alternativas debería garantizar el respeto de las RMI). En el marco de las utopías de Nozick cualquier proyecto sería aceptable en tanto que sus miembros pudieran abandonarlo. De este modo, todo el andamiaje teórico de Nozick parece reducirse a la idea peregrina de que si existen opciones y uno ha aceptado una de ellas, entonces se ha elegido libremente y no hay de qué quejarse (NOZICK, 1991, p. 309).

Empero, para Nozick la idea del "si le gusta bien y se no se va" no parece de aplicación universal, sino sólo aceptable en pequeñas comunidades "cara a cara", pues en estas últimas las personas deben confrontar directamente con sujetos cuyas actitudes podrían resultar ofensivas. Así, una comunidad puritana podría prohibir que sus habitantes practiquen sexo en la vía pública y una comunidad igualitarista podría impedir que alguien negocie un contrato para beneficio personal. Ahora bien, evitar la ofensa no es algo que nos autorice a violar las RMI; así pues, Nozick da un segundo argumento para justificar la regla de "lo toma o se va". En las comunidades pequeñas, los ciudadanos podrían ser dueños en forma conjunta del territorio, por lo que podrían prohibir que se realizaran ciertas prácticas en el mismo. No obstante, dado que la propiedad conjunta no podría existir a escala nacional, a menos que se lograse una- 
nimidad, nada podría prohibirse o exigirse de los ciudadanos (NOZICK, 1991, pp. 309-310). Sin embargo, admite Nozick:

...algunas comunidades cara a cara no estarían asentadas en tierra cuya propiedad sea tenida conjuntamente. ¿Puede la mayoría de votantes de un pueblo pequeño establecer una ordenanza contra cosas que encuentre ofensivas que sean hechas en la vía pública?... ¿[Acaso] La vasta mayoría tiene que enclaustrarse ante la minoría ofensiva? Si la mayoría puede determinar los límites sobre la conducta detectable en público, ¿puede, además, requerir que ninguno aparezca en público sin ropa, requerir también que ninguno aparezca en público sin usar un gafete que certifique que ha contribuido con $\mathrm{n} \%$ de su ingreso para los necesitados durante el año, con base en que se encuentra ofensivo mirar a alguien que no use ese gafete (que no ha contribuido)? ¿Y de dónde viene el derecho de la mayoría para decidir?... Como no veo mi camino claramente a través de estos problemas los planteo sólo para dejarlos [sin tratar](NOZICK, 1991, p. 310).

A pesar de que Nozick no haga más que presentar dudas; a pesar de que los ejemplos que brinda son por lo demás extraños, interesa notar que nuestro autor parece haber pasado de negar todo derecho a las mayorías a otorgarles carta blanca no sólo para redistribuir, sino también para imponer cualquier tipo de comportamiento. Es cierto que Locke (2001, II.95-99, pp. 468-472) parecía tener una fe moralmente ciega en las mayorías, ya que su capacidad de obligar vendría a ser explicada físicamente. Sin embargo, el poder de la mayoría lockeana estaba claramente subordinado al Bien Común, que a su vez debía interpretarse siempre a la luz de la Ley natural (LOCKE, 2001, II.135 y 163, pp. 504-505 y 531). En el caso de Nozick, las mayorías no deberían, en principio, poder rebasar las RMI de ningún individuo; no obstante lo cual, Nozick deja abierta la puerta para que lo hagan en caso de que algún individuo resultara ofensivo. En este punto, el filósofo norteamericano indica que los problemas que se le presentan a su teoría podrían resolverse acudiendo a la teoría del gobierno civil de Locke (la referencia es al capítulo VII del Segundo Tratado). Pero si acudimos a Locke deberíamos dejar de lado lado la idea de las comunidades cara a cara en la que las RMI de los individuos entran en conflicto y volver a reflexionar al nivel de la política 


\section{4}

nacional. Más aún, de volver a la política de Locke, no deberíamos pensar en individuos, sino en pueblos, ya que la teoría lockeana del gobierno civil se basa justamente en la formación de colectivos políticos que procuran el Bien Común (Common-wealth). Pero Nozick no da este paso, apenas parece señalar que el de Locke podría ser un camino a recorrer; lo que hace, en cambio, es oscilar entre sus teorías de los derechos y las titularidades y ciertas reflexiones extrañas al andamiaje liberal.

En cierto sentido, pareciera que Nozick pasa de ser del paladín del neoliberalismo a una suerte de comunitarista sui generis. Pero, a diferencia de los autores que participaron del debate liberal-comunitarista (y, otra vez, a diferencia de Locke), Nozick apenas sobrevuela la cuestión de la tolerancia, que sería fundamental para resolver los problemas que él mismo se plantea. No es que el tema de la tolerancia no aparezca en AEU, lo que sucede es que la tolerancia es imposible desde la perspectiva de individuos protegidos por derechos absolutos, inviolables y exhaustivos.

En sus Cartas y su Ensayo sobre la Tolerancia, Locke presentaba una visión de la tolerancia que, si bien era limitada en algunos aspectos (DURST, 2001), no dejaba de poseer cierto atractivo: la idea básica era que se debía tolerar al otro no porque pudiera tener razón sino porque merecía ser respetado. Locke no predicaba la tolerancia teniendo en vista la pluralidad o la contingencia de los valores, como lo harían más adelante la mayoría otros liberales (STUART MILL, 2008); no se basaba en el escepticismo, sino en la convicción del valor de la razón y, consecuentemente, en la importancia de no excluir a nadie cuyas acciones no atentasen en sistemáticamente contra el Bien Público (LOCKE, 1999). Desde la óptica lockeana, no había dudas de que hay una visión correcta (el cristianismo) y una miríada de visiones erradas. No obstante, del "error" de las segundas no se desprendía la necesidad de su prohibición; más bien al contrario, las ideas disímiles deberían ser aceptadas y, en la medida de lo posible, re-encausadas hacia la consecución del bienestar de la comunidad (CHEN, 1998; LORENZO, 2003; TUCKNESS, 2002). En principio los planteos de Locke y Nozick parecen compatibles; no obstante, esta apariencia se desvanece cuando consideramos que Nozick rechaza los conceptos de Comunidad y Bien Común que Locke precisa tomar en cuenta para darle sentido a su visión de la tolerancia. Así, sobre esta 
cuestión, nuevamente Nozick parece acudir a Locke, pero en realidad está haciendo un uso instrumental de un parte de su teoría.

\section{De la utopía a la distopía}

En AEU, Nozick se muestra de acuerdo con otros teóricos modernos respecto a que es posible construir metaprincipios de libertad que sólo definen las condiciones formales de una sociedad libre sin especificar contenido alguno. Esta característica es lo que hace que el Estado mínimo se convierta en un "estimulante" marco para las utopías, donde nuestros derechos son respetados y donde podemos fundar pautas comunitarias dentro de las cuales nos resulte agradable vivir, siempre y cuando respetemos el derecho de irse a quienes elijan reglas diferentes a las nuestras. Empero, aunque en principio el camino está abierto para que florezcan todas las utopías imaginables, de la argumentación de Nozick se desprende que en este hipotético "mercado de comunidades" se verificará una tendencia dominante del proyecto (como comunidad) del Estado mínimo. Esto es, dado que el Estado mínimo (en cuanto marco para las utopías) facilita la competencia entre proyectos, será lógico suponer que algunos serán preferidas a otros; y dado que el proyecto del Estado mínimo (en cuanto proyecto comunitario) es el único justo en sí mismo será, comprensiblemente, elegido por una amplia mayoría. En este punto no acaba de quedar claro si tiene sentido continuar distinguiendo entre el Estado mínimo como marco y como comunidad, pero debe reconocerse que, se tenga o no en cuenta la distinción, el Estado mínimo de Nozick supone la ausencia de la política.

En efecto, tal como ya señalamos, el Estado mínimo de Nozick no surge como producto de la política, es el emergente de una situación ideal de mercado que se supone moral. El Estado mínimo es una instancia de protección de derechos moralmente definidos y por lo tanto incuestionables; así, su tarea cotidiana es meramente administrativa. Pero no se trata de una administración creativa o prospectiva (no es la política arquitectónica de la que hablaba Platón y ni siquiera se busca el Bien Público como en Locke), sino de una gestión limitada a minimizar las violaciones a las RMI. Por otra parte, el Estado mínimo de Nozick no 
admite siquiera un momento "extraordinario", como el que estaba implicado en el derecho a la resistencia en la visión de Locke (2001, II.231232, pp. 588-589). En una hipotética situación de disconformidad (incluso unánime) con la marcha del gobierno, los ciudadanos de Nozick no pueden hacer otra cosa que resignarse.

Dicho más crudamente: en la sociedad de Nozick (que es una suma de individuos) el Estado no es creado políticamente, no tiene objetivos políticos, no se maneja a través de la política y tampoco puede ser cuestionado a través de la política. Aun así, la sociedad imaginada por Nozick podría funcionar si estuviese formada por individuos racionales que se rigieran (casi) siempre por lo metaprincipios normativos pero sólo si sus intereses no fueran opuestos. En efecto, cuando el conflicto de intereses se incorpora al análisis, el conflicto de derechos también se hace presente y, no habiendo racionalidad ${ }^{8}$ o instancia política de resolución, la sociedad de Nozick se torna imposible.

Hay que reconocer que Nozick no es el primer pensador que plantea una sociedad en la que la política está ausente. La idea puede rastrearse en muchos filósofos políticos liberales. Pero autores como Locke y Kant (por no mencionar a liberales modernos como Hegel y Stuart Mill) no proponen eliminar la política, sino obturarla, limitarla, sustraerla del escrutinio de las pasiones populares. Nozick, en cambio, no deja ningún espacio libre, ningún resquicio por o en el cual la política pueda expresarse. La única instancia "política” que puede ser aceptable para Nozick es un Estado mínimo limitado a hacer cumplir las RMI. Pero ese Estado que parece limitado, dispone, en realidad, de un poder incuestionable, no porque sea incuestionable por principio, sino porque no hay canales de cuestionamiento; es decir, porque no hay política. Así, el planteo de Nozick parece ser más neo-hobbeseano que neo-lockeano.

Para concluir, digamos que la ausencia de la política en el planteo de Nozick es, de un modo paradójico, la arista más interesante de este filósofo. Y ello porque las tesis nozickianas nos muestran con una claridad meridiana hasta qué punto nuestra sociedad requiere de mucho más que un Estado mínimo para poder sobrevivir. En efecto, las sociedades precisan, además de reglas y autoridades que las hagan cumplir, una arena (una esfera pública) en la que se pueda deliberar sobre esas reglas. Es decir: las sociedades requieren de política.Y si, efectivamente, se acepta el 
desafio de retornar a lo político, necesariamente se deberá retomar una categoría (problemática pero imprescindible) que era la base de la reflexión lockeana: el Bien Común.

${ }^{1}$ Este punto, que Nozick menciona de pasada en su discusión con el utilitarismo, debe ser enfatizado, pues es el que le permite a Nozick "derrotar" cualquier reclamo de justicia, por intuitivo que sea (GAR GARELLA, 1999).

${ }^{2}$ Aun en los textos críticos, Kant $(1983 ; 1989)$ continúa pensando que la auto-propiedad no puede ni suponerse ni aceptarse y por ello el hombre no tiene derecho a quitarse la vida.

${ }^{3}$ Según Nozick, la sociedad existe apenas como sumatoria de individuos; entonces, el bienestar social no puede ser otra cosa que el mejoramiento (en sentido paretiano) de al menos un agente sin caer en el empeoramiento de nadie.

${ }^{4}$ Ley Natural que incluía no sólo el derecho (negativo) a no ser dañados en nuestras vida, libertad y bienes, sino tam-bién el deber (positivo) de no dañar la vida, la libertad y los bienes de los otros y, consecuentemente, la obligación moral de la caridad. En este sentido, vale la pena resaltar que la caridad lockeana (LOCKE, 2001, I.42-43, pp. 244-245) es diferente a la filantropía nozickiana (NOZICK, 1991, pp. 257-260). Siguiendo a Locke, el deber de cada persona es auto-preservarse y preservar a la humanidad convierte a la caridad es un deber de aquellos que disfrutan de abundancia y un derecho (exigible) de aquellos que pasan necesidad (BOYD, 2002, pp. 46-52); en cambio de acuerdo con Nozick, obligar a las personas a ser caritativas violaría las RMI y por lo tanto sería moralmente inaceptable.

4 Así, la agencia-Estado surge por un proceso como un "síntoma del mercado" (ÎIÎEK, 1992).

5 Este problema ya estaba presente en la teoría lockeana del consentimiento tácito (LOCKE, 2001, II.121, p. 493).

${ }^{6}$ Una comunidad que invirtió en la educación de sus miembros podría requerir una indemnización si uno de sus ciudadanos que fue a su universidad gratuita quiere dedicarse a ejercer su profesión en otra comunidad donde la universidad es paga, pero en la que existen mejores oportunidades profesionales (NOZICK, 1991, pp. 316-317).

${ }^{7}$ La racionalidad del sujeto de Nozick no es intersubjetiva, sino instrumental. De este modo, la democracia y el espíritu republicano no aparecen como contenidos necesarios sino como posibilidades más bien remotas. El problema entonces es que el Estado mínimo (ya sea como marco o como proyecto) no da garantías sobre cómo (y por qué) los ciudadanos podrían interpretar correctamente, en la práctica, los metaprincipios morales.

doispontos, Curitiba, São Carlos, vol. 7, n. 4, p.11-30, setembro, 2010 


\section{8}

\section{Referencias bibliográficas}

BOYD, R. (2002). The Calvinist origins of lockean Political Economy. History of Political Thought, vol. XXIII, n¹, pp. 30-60.

CHEN, S. (1998). Locke's political arguments for toleration. History of Political Thought, vol. 19, n², pp. 167-185.

COHEN, G. A. (1995). Self-ownership, freedom and equality. Cambridge, Mass.: Cambridge University Press.

COLEMAN, J. S. (1976). Review: Individual Rights and the State. The American Journal of Sociology, vol. 82, n²2, pp. 428-442.

DAVIS, L. (1976). Comments on Nozick's Entitlement Theory. The Journal of Philosophy, vol. 73, n²1, pp. 836-844.

DRURY, S. B. (1982). Locke and Nozick on Property. Political Studies, vol. 30, nº1, pp. 28-41.

DUNN, J. (1986). The Political Thought John Locke. An historical account of the argument of the Two Treatises of Government. Cambridge: Cambridge University Press.

DURST, D. C. (2001). The limits of Toleration in John Locke's Liberal Thought. Res Publica, vol. 7, nº , pp. 39-55.

FESER, E. (2004). On Nozick. s/d:Thomson/Wadsworth.

FESER, E. (2005). There is not such thing as a Unjust Initial Acquisition. Social Philosophy and Policy, vol. 22, nº1, pp. 56-80.

FRIED, B. (2003). 'IfYou Don't Like It, Leave It': The Problem of Exit in Social Contractarian Arguments. Philosophy \& Public Affairs, vol. 31, nº 1 , pp. 40-70.

GAR GARELLA, R. (1999). Las teorías de la justicia después de Rawls. Barcelona: Paidós.

KANT, I. \& RODRÍGUEZ ARAMAYO, R. (1988). Lecciones de Ética. Barcelona: Crítica. 
KANT, I. (1983). Fundamentación de la metafísica de las costumbres. Madrid: Espasa-Calpe.

KANT, I. (1989). La metafísica de las costumbres. Madrid: Tecnos.

LASLETT, P. (1988). Introduction to Locke: Two treatises of government. Cambridge \& New York: Cambridge University Press.

LOCKE, J. (1999). Ensayo sobre la tolerancia. Ensayo y carta sobre la tolerancia. Madrid: Alianza.

LOCKE, J. (2001). Dois tratados sobre o governo. São Paulo: Martins Fontes.

LOEWENBERG, R. J. (1985). John Locke and the Antebellum Defense of Slavery. Political Theory, vol. 13, n² 2, pp. 266-291.

LORENZO, D. J. (2003). Tradition and Prudence in Locke's Exceptions to Toleration. American Journal of Political Science, vol. 47, n², pp. 248-258.

MORRESI, S. D. (2009). Releyendo al 'padre del liberalismo'. In RINESI, E. (ed.), En el nombre de Dios. Razón natural y revolución burguesa en la obra de John Locke. Buenos Aires: Gorla.

NOZICK, R. (1981). Philosophical explanations. Cambridge, Mass.: Harvard University Press.

NOZICK, R. (1991). Anarquía, Estado y Utopía. México D. F.: Fondo de Cultura Económica.

NOZICK, R. (1997). Meditcaciones sobre la vida. Barcelona: Gedisa.

OLIVECRONA, K. (1974a). Appropriation in the State of Nature:

Locke on the Origin of Property. Journal of the History of Ideas, vol. 35, n², pp. 211-230.

OLIVECRONA, K. (1974b). Locke's Theory of Appropriation. The Philosophical Quarterly, vol. 24, nº6, pp. 220-234.

SINGER, P. (1976). Why Nozick is not so easy to refute. Political Research Quarterly, vol. 29, pp. 191-192. 
SREENIVASAN, G. (1995). The limits of lockean rights in property. New York: Oxford University Press.

STUART MILL, J. (2008). On liberty and other essays. Oxford: Oxford University Press.

TUCKNESS, A. (2002). Rethinking the Intolerant Locke. American Journal of Political Science, vol. 46, n², pp. 288-298.

TUlly, J. H. (1993). An Approach to Political Philosophy: Locke in contexts. Cambridge: Cambridge University Press.

DE VITA, A. (2000). A Justiça Igualitária e seus Críticos. São Paulo: UNESP-FAPESP.

WINDSTRUP, G. (1980). Locke on Suicide. Political Theory, vol. 8, n²2, pp. 169-182.

WOLFF, J. (1991). Robert Nozick: Property, Justice and the minimal state. Stanford: Stanford University Press.

ÎIÎEK, S. (1992). El sublime objeto de la ideología. México D. F.: Siglo XXI Editores. 